\title{
INVESTIGATION ON REFLECTION OF TECTONIC PATTERN IN ASG EUPOS DATA IN THE SUDETES AND ADJACENT AREAS
}

\author{
Zbigniew Szczerbowski
}

AGH University of Science and Technology,

Faculty of Mining Surveying and Environmental Engineering, Department of Mining Areas Protection, Geoinformatics and Mining Surveying, Poland,

\begin{abstract}
The GNSS data evaluated from on observation of ASG EUPOS stations in the Sudety Mts. and in adjacent areas is analyzed by the author in the scope of disturbances in daily solutions that can be induced by tectonics stress. The daily position changes derived from GNSS data demonstrate the long or short term trends, which are affected by offsets of different nature. Author presents an analysis based on frequency of parameter displacement vector azimuth. The aim of the analysis is to show statistical significance of observed small values of temporal displacements, which values are not normally distributed. There are "outliers" of the normal distribution of displacement azimuths, which values show a certain reproducibility, which corresponds to orientations of tectonic lines. That suggests small, short time movements along boundaries of horsts and grabens - a crustal-extension structure of the area. However derived results (values of displacements) are less than a limitation error, temporal distributions of coordinates are not random as usually data errors. So in author's opinion the spatial-temporal evolution of horizontal displacements of ASG EUPOS stations in the Sudety Mts. and in adjacent areas are determined by expressions of underlying geological structures.
\end{abstract}

Keywords: neotectonics, permanent GPS/GNSS observations, lineaments, horizontal displacements.

\section{Introduction}

One of the reason of surprising development of geodynamic studies along with progress in instrumentation is a lack of knowledge about geotectonic evolution or natural laws and processes that operate in geosphere. In regional or local scale acknowledging the mechanism of the processes has an engineering sense too. Geodynamic investigations in civil engineering, geotechnical engineering, mining engineering etc. are often needed to achieve an understanding condition of the area 
in or on which engineering activity will take place especially to assess risk to humans, property and the environment resulting from natural hazards such as earthquakes, landslides etc. The presented study deals with deformation field in the Sudetes and adjacent areas, which became a test area of many teams of researchers representing a range of disciplines. Since tectonic activity of the Sudetes is a subject of widespread interest, the keystone is to build research networks, to make international connections and international projects and finally data exchange and multidisciplinary data elaboration (see: Cacoń et al., 2004; Kaczmarek et al., 2016). The presented study concentrates on displacements in the Sudetes and adjacent areas, especially in Fore-Sudetic Block exploring GNSS data evaluated from observations carried out in ASG-EUPOS permanent stations. In presented approach horizontal coordinates (topocentric frame) are analyzed and the author combines their values to investigate horizontal displacements vectors. So, having station position $(\varphi, \lambda), \bar{X} \bar{Y} \bar{Z}$ assumed as starting and $\mathrm{XYZ}$ coordinates for particular observation (ETRF2000) a conversion from geocentric to topocentric frame using rotation matrix was derived for as follows to obtain components of displacement vector :

$$
\begin{aligned}
& N=-\sin \bar{\varphi} \cdot \cos \bar{\lambda} \cdot(X-\bar{X})-\sin \bar{\varphi} \cdot \sin \bar{\lambda} \cdot(Y-\bar{Y})+\cos \bar{\varphi} \cdot(Z-\bar{Z}) \\
& E=-\sin \bar{\lambda} \cdot(X-\bar{X})+\cos \bar{\lambda} \cdot(Y-\bar{Y}) \\
& U=\cos \bar{\varphi} \cdot \cos \bar{\lambda} \cdot(X-\bar{X})+\cos \bar{\varphi} \cdot \sin \bar{\lambda} \cdot(Y-\bar{Y})+\sin \bar{\varphi} \cdot(Z-\bar{Z})
\end{aligned}
$$

In fact variation of directions as attribute of the vector is examined. The data depicting movements of following ASG-EUPOS stations located in the area of interest were examined: Głogów (GLOG), Jelenia Góra (JLGR), Jesenik (CJES), Kłodzko (KLDZ), Krotoszyn (KROT), Legnica (LEGN), Leszno (LESZ), Liberec (CLIB), Nysa (NYSA), Svitavy (CSVI), Trutnov (CTRU), Wałbrzych (WLBR), Wrocław (WROC), Zittau (0147), Zary (ZARY). In fact they are located nearby the Sudetes, areas adjacent to the Sudetes and in far forefield of the mountains (Fig. 1).

The main problem initially analyzed in the paper is randomness of displacements demonstrated by some ASG-EUPOS stations located in the mentioned above area. The problem of non linearity of GPS permanent stations was studied in many leading papers and the problem was discussed in (Bogusz, 2015). The author concludes that non-linearity of the GPS-derived velocities is not evident and proves the trend nonlinearity for stations in tectonically active areas.

\section{Problems of tectonic movements detection and tectonic activity of the investigated area}

Long term permanent observations of displacements evaluated from GNSS measurements provide facts about natural or anthropogenic movements. Identification of effects induced by natural processes as tectonic movements or phenomena as mining tremors (Szczerbowski and Jura, 2015) can be difficult, when observed values of displacements are small or their performance is accidental. Appropriate statistic approach is necessary then to distinguish data representing effects of supposed process/phenomenon. 

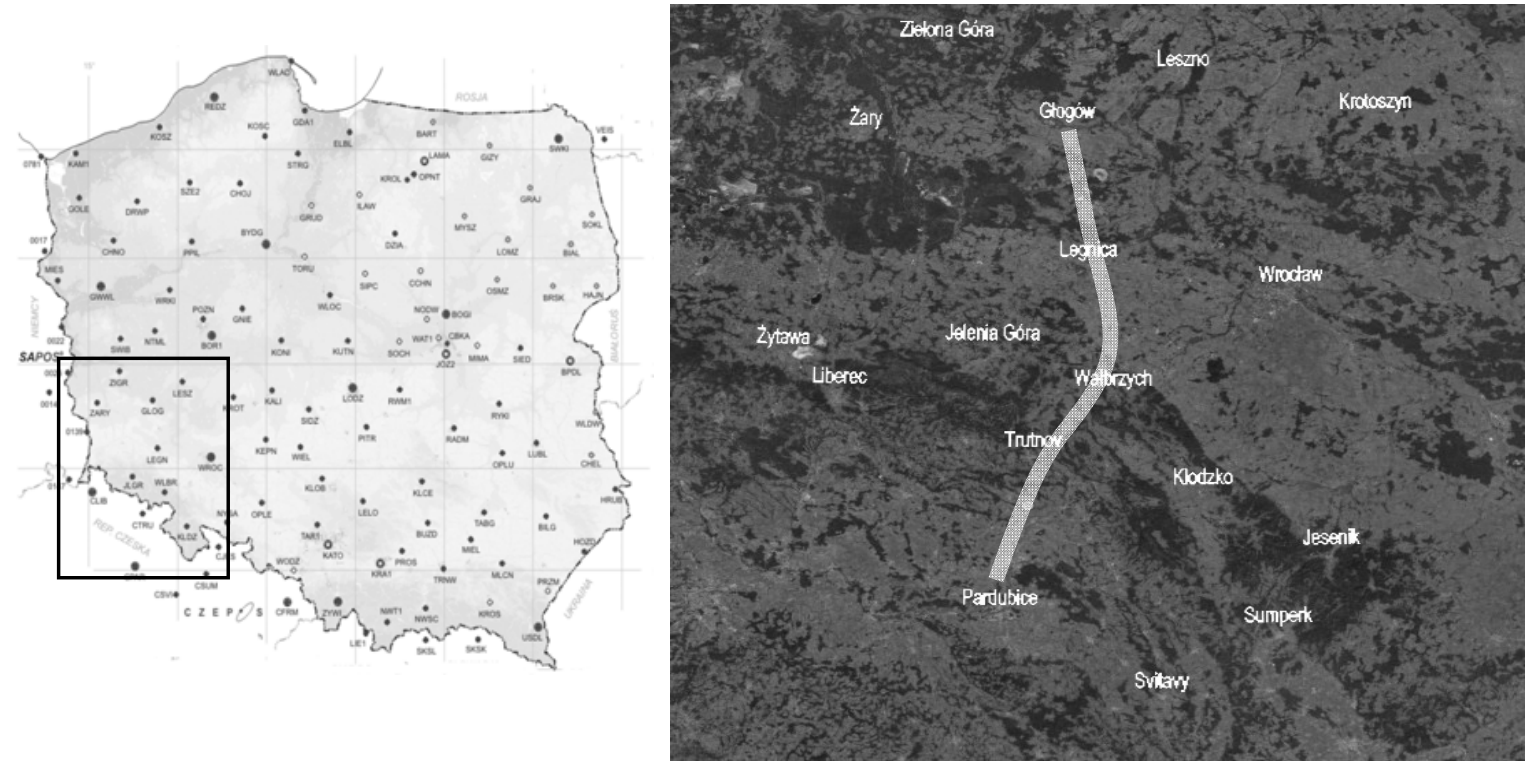

Fig. 1. The ASG EUPOS station in the area of the study and localization of profile line discussed in the text.

Among geological processes or phenomena, which effects are observed by GNSS technique tectonic movements play a leading role. Analyzing data it should be presumed that observed displacements can be a resultant of a combination of reasons. But effects of geological process or phenomenon could be not measurable or not clear to be observed due to not stationary or non continuous performance (Liszkowski, 1982).So, local tectonic stress can be a manifestation of tectonic activity, where small displacements or other deformation factors are not measurable by classical geodetic measurements due to poor accuracy or occasional performance of the movements. Some geological-based reasons as seismic-related phenomena are possible to be monitored by permanent GPS observations at high sampling rates (Hefty and Gerhátová, 2012). Monitoring of very small and occasionally-occurring tectonic movements requires even more challenging techniques. Effect of tectonic processes/phenomena can be revealed then as so called tectonic events by instruments working permanently with micro or nano-meter accuracy. Kaczorowski and Wojewoda (2011) report several tectonic events in area of the Sudetes. The events were observed in Geodynamic Laboratory in Książ (Fig. 2) and their manifestation was determined by extensometers as a tension caused by tectonic stress. This is one of example of wide range of neotectonic investigations carried out in the Sudetes and adjacent areas. The results were discussed in a number of papers by many authors (Dyjor, 1993; Grygar and Jellnek, 2003; Kontny, 2003; Wojewoda, 2007). 


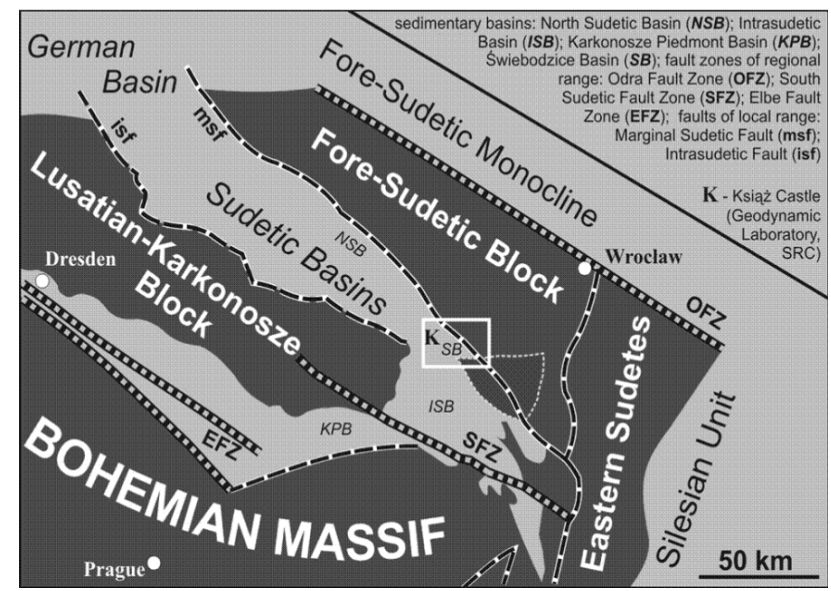

Fig. 2. Geological background of the studied area (according to Wojewoda, 2007; Kaczorowski and Wojewoda, 2011).

Recent geodynamic activity of the Sudeten and adjacent areas confirmed by the results of geodetic, geophysical and other test works in some areas. The maximal vertical changes were found in areas nearby following locations (Kaczmarek et al., 2016): Svitavy (subsidence $-0.6 \mathrm{~mm} / \mathrm{y}$ ), Trutnov and Kłodzko (uplift $+0.8 \mathrm{~mm} / \mathrm{y}$ ), Jelenia Góra (subsidence $-0.8 \mathrm{~mm} / \mathrm{y}$ ). This very important results should be analyzed in the scope of relation to geological location. Major elements of the geological structure of the investigated area with systems of blocks and basins are outlined in Fig. 2. The Sudetes, the most distinct tectonic zone there has been formed within three successive scenarios discussed in detail by Wojewoda (2007). The effect of long-time tectonic deformation is a system of horsts and grabens, system of faults including large regional faults. Such a geological scheme with pattern of tectonic lines involves a stress field pattern as its expressions in detected displacements (Wojewoda, 2007; Kaczmarek et al., 2016). A role of tectonic lines in mining tremors in Polish cooper mines in Fore-Sudetic Monocline is widely discussed in the paper by Orlecka-Sikora et al. (2009). A statistical relationship (in conformity of position and lineament directions with vectors of epicenters of the underground tremors) between lineaments on satellite images and high-energy induced seismic activity in the mines was reported by Pilecka $(2007,2008)$. More about geology of the area an its tectonic activity could be found in the papers by Dyjor (1993) and Salski (1996).

Considering block pattern in geological structure of the area and assuming tectonic activity of the area a question to be asked is whether it is possible to recognize tectonic effects in varying values of GPS/GNSS observations.

Although the main of goal of the paper isn't a finding effects of tectonic process in GPS permanent stations data but the author's intention is to suggest another approach in analysis of the stations coordinates examining azimuths of displacement vectors. The basic problem is if varying in time coordinates are always a simple combination of known, geologically induced changes (movement of tectonic plates etc.), seasonal effects (hydrogeological impacts etc.) and random errors. So, the question is: do horizontal coordinate time series comprise random effects reflecting small impulse of a tectonic source? To answer the question and before undertaking research work the author would like to highlight two issues that seems to be very important. The first is what kind of tectonic signal is expected to be revealed: stochastic as functions of time parameter (input: deterministic argument) or random, 
uncorrelated in time and which sequence is statistically uncorrelated. The second is how to find non periodic tectonic signals in GNSS observation.

\section{Data analysis and results}

Taking a number of geodynamical test fields, control points or research methods and techniques the studied area is one of the most investigated in Europe as a place, where recent crustal movements are revealed. Between geodetic measurements application of precise leveling and GPS/GNSS observations are crucial in detection of tectonic activity. Permanent GPS/GNSS observations are applied as well (Schenk and Schenková, 2008; Bogusz et al., 2012). The permanent GNSS stations play increasing role in the investigations especially since June 2nd, 2008 when the ASGEUPOS (Active Geodetic Network), a system for precise satellite positioning in Poland started to operate with full operability (Bosy et al., 2007). So, many studies in geodynamics utilizing the system has been applied and a great number of papers were devoted to regional and also to local aspects of geodynamics (Bogusz et al., 2012, Kontny and Bogusz, 2012). Some of the stations were involved in the system in later dates as analyzed in the text Pardubice (CPAR), Jesenik (CJES ) or Svitavy (CSVI ) joined in 2010.

Presented reasoning and estimations are based on N,E components of displacement vector retrieved from data from ASG-EUPOS system as daily solutions (outcomes). The details concerning navigation data processing are available at www.asgeupos.pl. This methodology is beyond the scope of this research. According to the system's general standards the accuracy of daily horizontal results is about 2 $\mathrm{mm}$ for each coordinate (Araszkiewicz et al., 2009; Figurski et al., 2010). However, this value is in fact uncertainty estimated in average can be stated more precisely for data from individual station.

Displacement vectors are considered and the reasoning encompass values transformed to local coordinate system. First look of the distribution of horizontal components values usually show a significant outliers often exceeding the error bands. Of course, estimated values of daily outcomes (solutions) were influenced by many errors and the precision of the data can be changing in time but presuming that outliers are really errors their distribution should be random. The basic problem with time series approximating the distributions of coordinates values $(X, Y$ or $Z$ in geocentric frame) is in their real stationary state and time dependence of values. Presuming outlying values in $X$ coordinates are random there should be no relation with the values of $Y$ coordinates. So, in opposite, the changes of $X$ coordinates should involve some relation with changes of $Y$ coordinate reflecting effects of a process or phenomenon. However, horizontal displacements are analyzed, the coordinates were transformed from the geocentric to topocentric frame and only horizontal components of displacement vectors were studied (N,E components). A term "horizontal displacement" means here a vector that specifies the change in horizontal position of a station (determined by coordinates evaluated as daily solutions) relative to a previous position, should demonstrate orientation in time. In that case it can be considered as a kinematic manifestation, which is reasoned by a certain, maybe unknown or not to be identified factor. So, this manifestation presumed as infrequent is analyzed here and orientations (azimuths) of horizontal displacement vectors are examined. There are two approaches undertaken in the analysis in examination of displacements. First is for changes in horizontal position related to the position determined for the first day of measurements i.e. a starting 
moment of ASG-EUPOS. This change of the position is defined in the paper as total displacement (total vector). The second type are changes in horizontal position day by day and this change is called daily displacement (daily vector). But it should be realized that changes between daily records of coordinates or azimuths just provide information about variance of the data. Due to limitation of the paper size detailed results of successive steps of analysis are presented only for some stations. So, stations located nearly linearly and alone a line nearly longitudinally passing block of the Sudetes: CPAR, CTRU, WLBR, LEGN, GLOG, LESZ (Fig. 1).

\subsection{Values of the components of displacement vectors}

Usually the changes of $X, Y, Z$ coordinates in time are presented in the form of line graphs. Assuming stochastic distribution of coordinates in time, application of smoothing methods and trend extraction is a typical approach in post-processing. However, not distribution of a single coordinate is considered but displacement as changes in of station's position are presented in a perceptual form as positioning map (Fig. 3). Such a presentation reveals orientation of a set of data points (a station's positions) as a probable tendency in potential movements of particular station. As it is shown on Fig 3. changes of the stations' positions form point clouds, which reveals some tendencies as elongated shapes (e.g. CTRU), especially in total displacements. Although a general form in the most cases remains error ellipses some there could be some tendencies (as repeatability) in points' positions.

To find movements don't manifesting temporal order but in random events revealing a tendency in direction of displacements another approach is required. So, values of changes in horizontal components of displacement vector (daily solutions) were examined in the scope of probability distribution. To investigate non random effects in measurements repeatability of measured values was analyzed. In order to do this histograms of N,E daily changes for the selected stations were made (Fig. 4).

Assuming steady state of the stations (not moving, no displacements) the histograms should be centered over the zero value of each component. For total displacements a shift is expected as a result of arbitrary assumed the first, initial value (moment that ASG-EUPOS system started) as a reference one. To compare results of the daily results of the selected station. Constructing a histogram the first step was to "bin" the range of values. For presented distributions bins are of equal size: $0.5 \mathrm{~mm}$ as the range of frequency axis. As would be expected from the Central Limit Theorem (Brandt, 1999), the acquired data should be normally distributed if a station is in steady position. The mean occurs at the center of the distribution, and represents the best estimate of a daily displacement along particular coordinate based on all of the measured data (Klos et al., 2015). Appearance of histogram, a visual representation of the statistical significance suggests tendency in measured values. Although all calculated medians are very close in value to zero, peak of histograms or asymmetry of histograms show temporal movements of the station.

Another perception can be drawn from histograms outlining distribution of daily and total displacement vector values of the mentioned stations. Mean value as the most frequent value of all the stations is about $1 \mathrm{~mm}$. And this value can represent as a rate of displacement process but the most frequent value of phenomenon. For total displacements average and mean values vary from $0.5 \mathrm{~mm}$ (CTRU) to $2.5 \mathrm{~mm}$ (GLOG). But for histograms of total displacements distribution are different in shape: they have usually negative skew and they are more flat than histograms of daily 

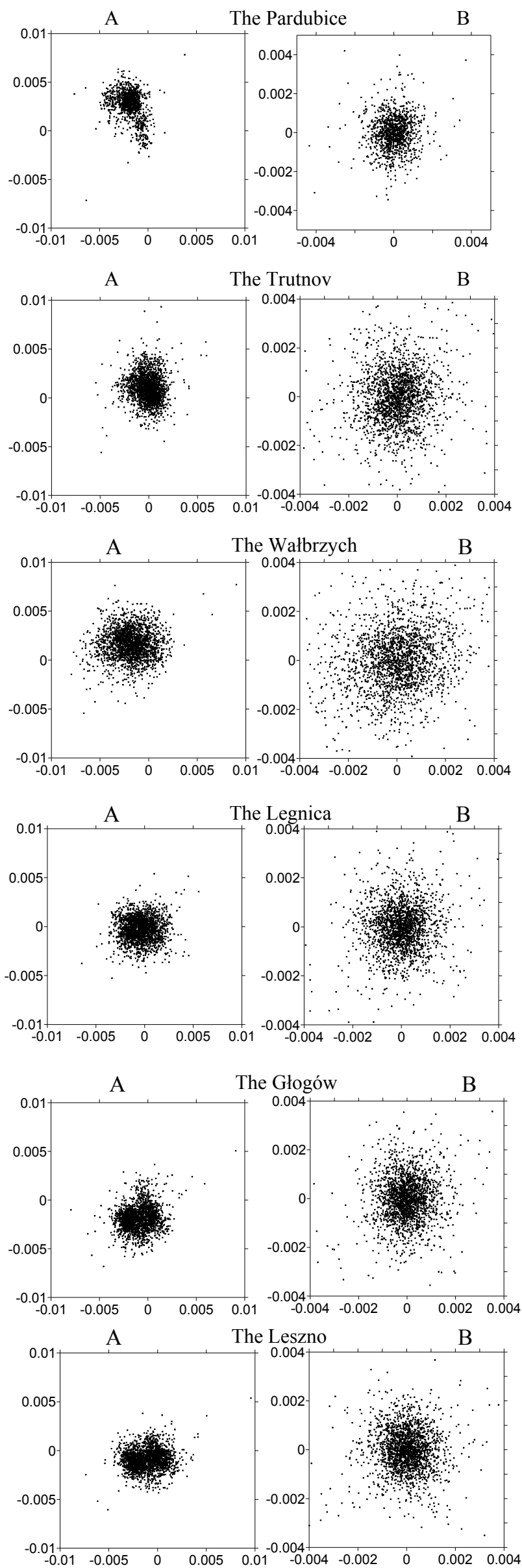

Fig. 3. Daily $(A)$ and total (B) displacements [m] observed in the analyzed stations. 


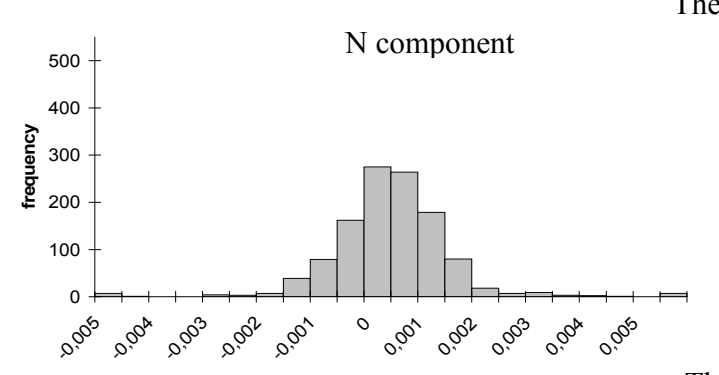

The Pardubice
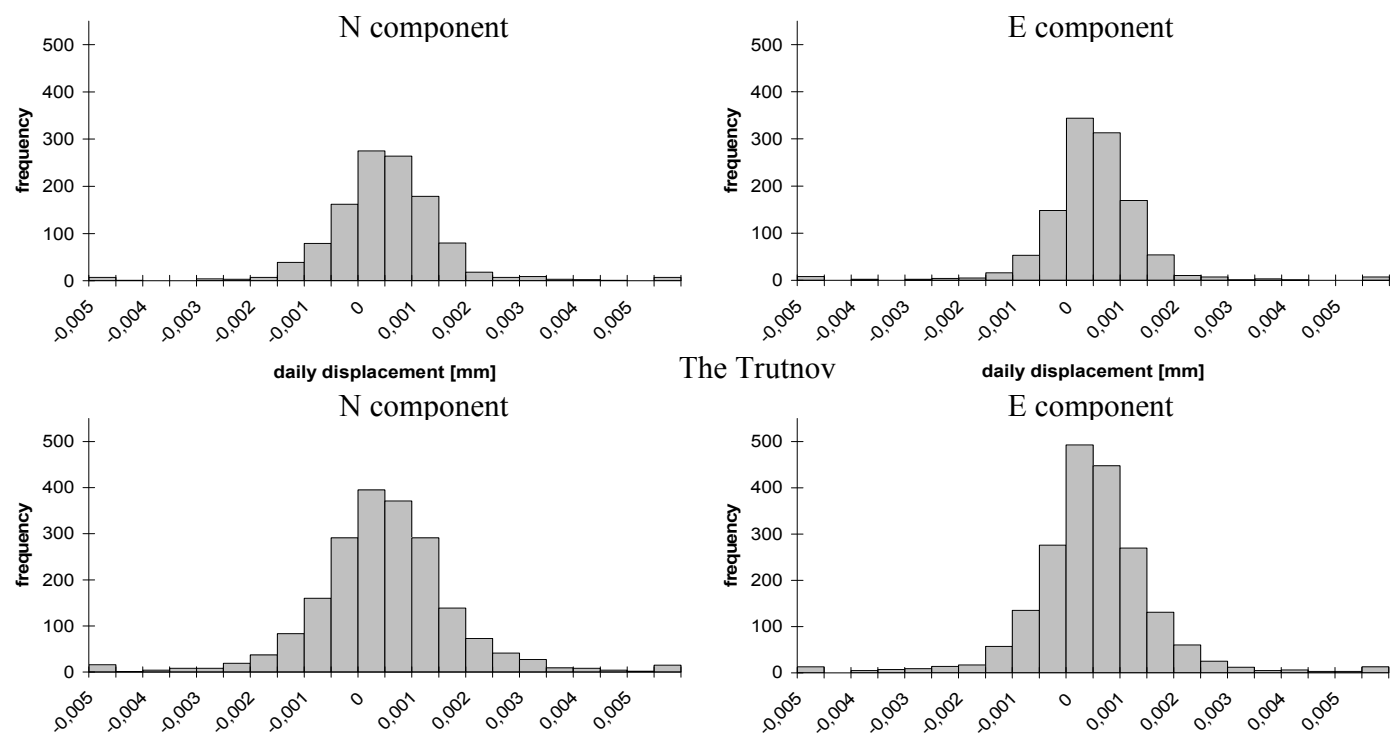

The Trutnov

daily displacement $[\mathrm{mm}]$

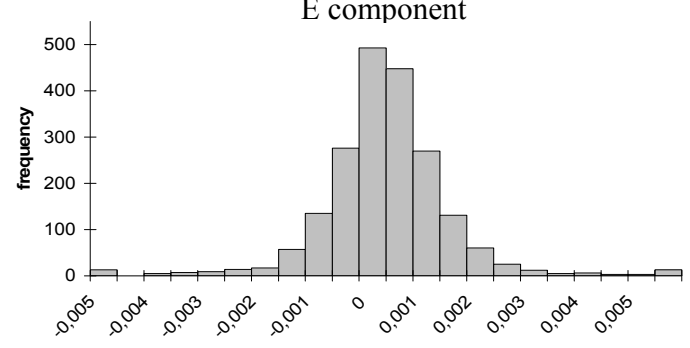

E component

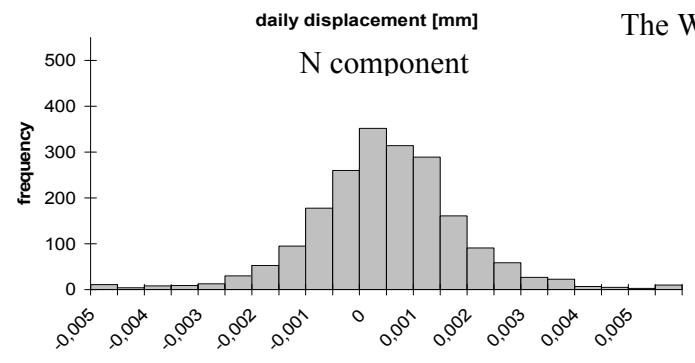

Wałbrzych daily displacement $[\mathrm{mm}]$
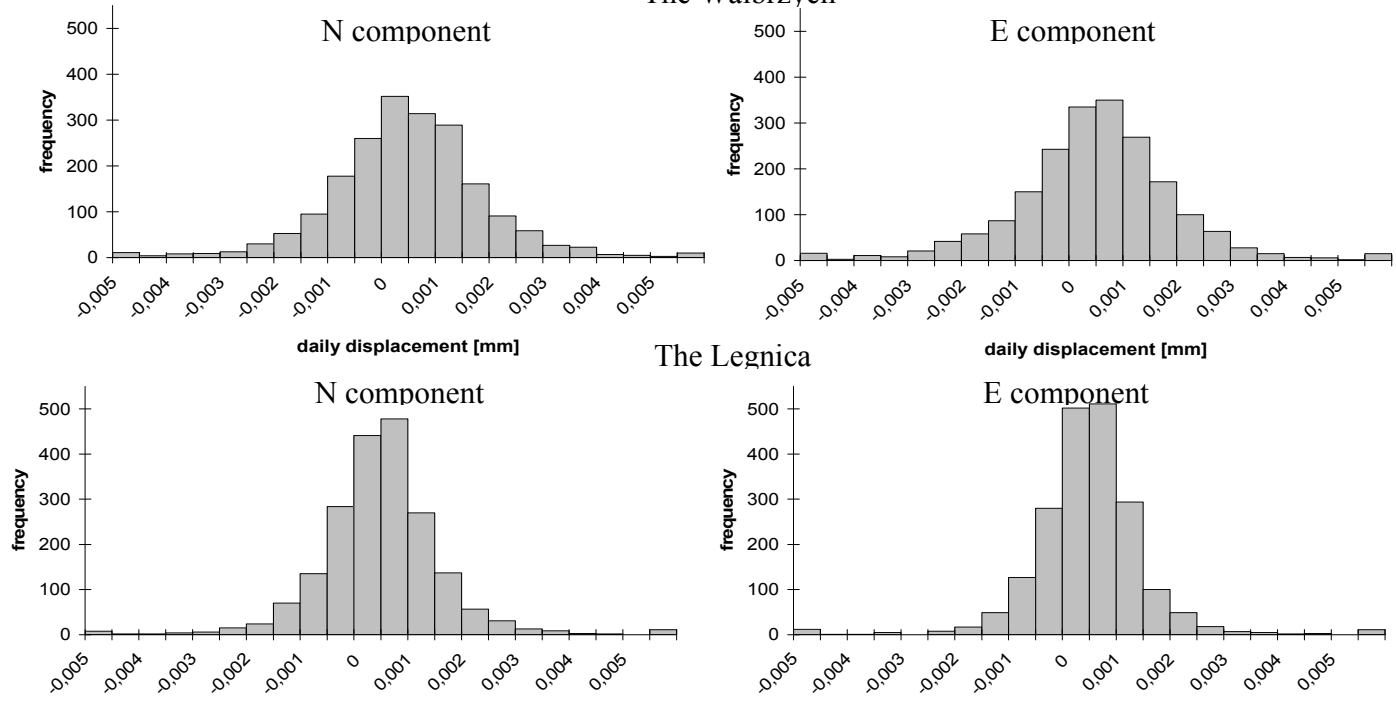

The Legnica daily displacement $[\mathrm{mm}]$

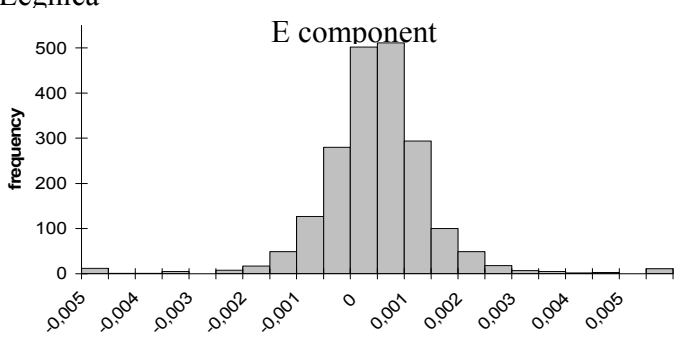

aily displacement $[\mathrm{mm}]$

The Głogów
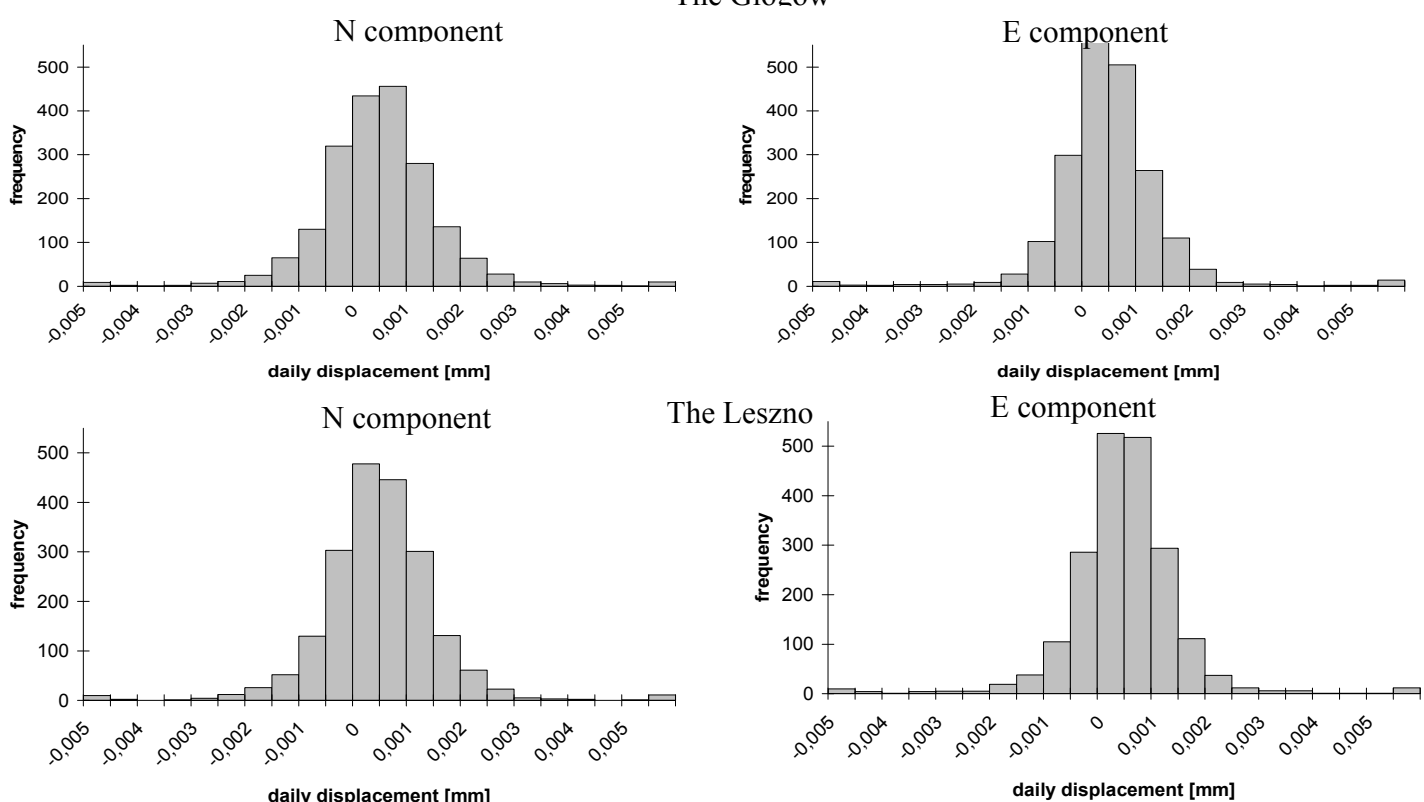

Fig. 4. Histograms of daily displacements of the analyzed stations. 
displacements (having mostly positive skew). That can be explained as slow cumulative effect of temporal displacements.

Statistically significance of statistical measures isn't a subject of the paper. Key question is a possible relation between changes in $\mathrm{N}$ and $\mathrm{E}$ components and its significant repeatability as a representation of evident displacements. In order to do this analysis of azimuths was carried out.

\subsection{Azimuths of the displacement vectors}

The mentioned before changes of the N,E components can reflect the displacements if changes in orientation of displacement vector show a significant tendency. Real displacements conditioned by geological should reveal in correlation between $\mathrm{N}$ and E components should demonstrate tendency especially in orientation of the changes in station's position. So, frequency of the azimuths of daily and total displacements were examined and evaluated results are outlined in Figs. 5 and 6.

The figures present rose diagrams, which are polar histograms displaying directional data: azimuths of daily and total displacement vectors and frequency of each 10-degree class interval. Having mostly over 2000 records and 36 intervals average frequency value for each class is about 60 cases. It was presumed that over 90 hundred cases (over $150 \%$ of average cases) in a class interval is over representation in distribution of azimuths suggesting a directional tendency. For the stations, where the number of observation is lower that over representation will be proportional lower - still over $150 \%$ of the average. So, interpretation of the tendencies are different for total and daily changes. Fig. 7 presents of overrepresented daily displacement vectors of the analyzed stations The overrepresenting azimuths distinct from the other their statistical repeatability, however it doesn't mean a causality and implication of existing reasons. So, repeatability as statistical correlation does not imply causation but it could be a hint in investigated tectonic patterns in changes of the stations' positions. The next figure combines number of observed azimuths of daily displacements of the stations (Fig. 8). The distribution of over-represented values of the azimuths was analyzed in this time in 20 degree class intervals. The distributions of compared azimuths show minima and maxima. Although most of them were derived from small values of the components' changes, within the range of errors, the patterns of frequencies doesn't seem to be accidental. Furthermore, dominant values of daily displacements don't involve unambiguous orientation of total displacement vectors presented in Fig. 5. Daily changes have a relative sense and they illustrate how station's position is changing in short time, total changes illustrate overall directional tendency although initial position as it was discussed before was arbitrary established. In overall the predominant direction of total displacements corresponds to orientation of point cloud representing positions of a relevant station. However, distributions of azimuths of daily and total displacements look different there is a certain relation. For the station demonstrating clear direction of total displacements (CPAR, WLBR), daily displacements seems to be a kind of correction for "keeping" course of the movement and directions of their over represented cases (azimuth intervals with more than 150 $\%$ of average value) are perpendicular to them. 
The Pardubice

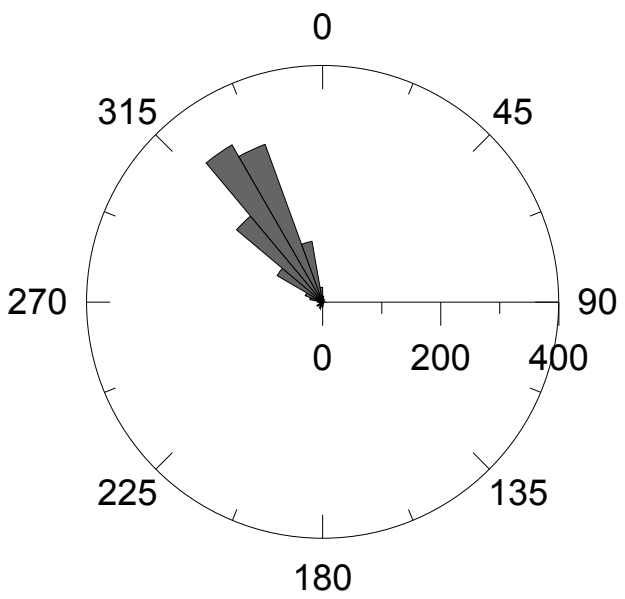

The Wałbrzych

0

315

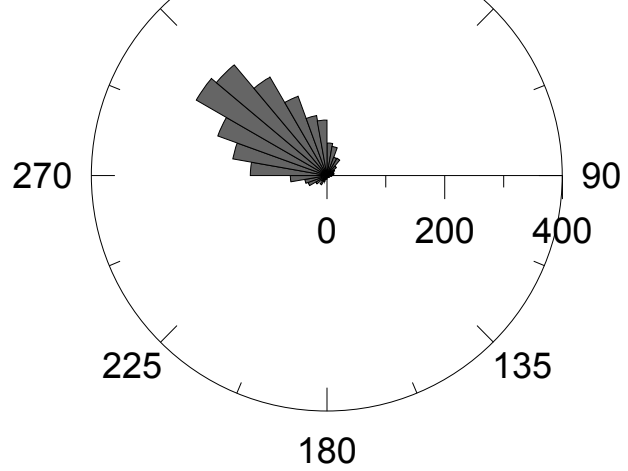

The Głogów

0

315

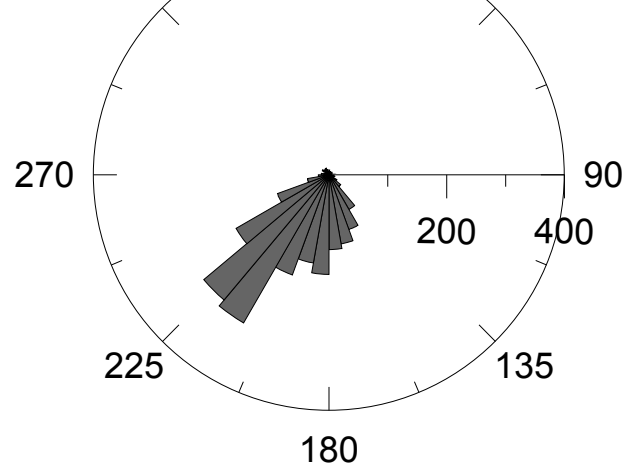

The Trutnov

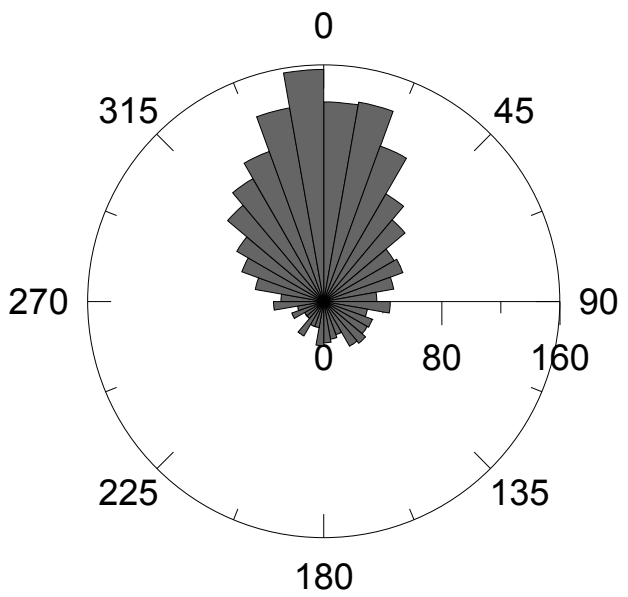

The Legnica

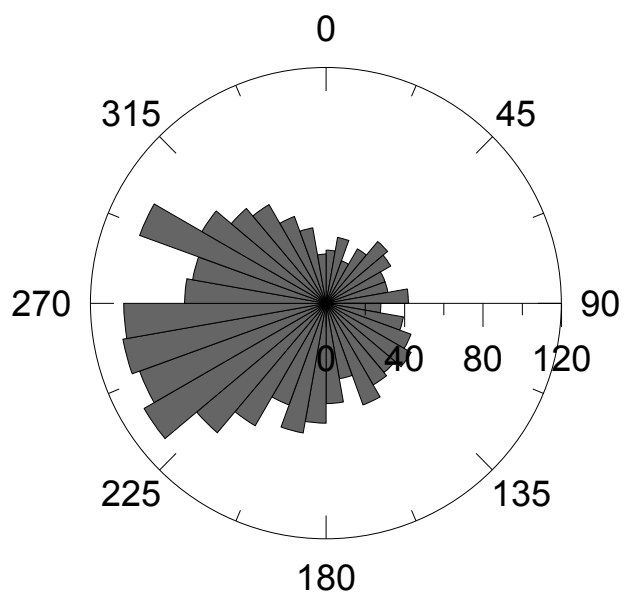

The Leszno

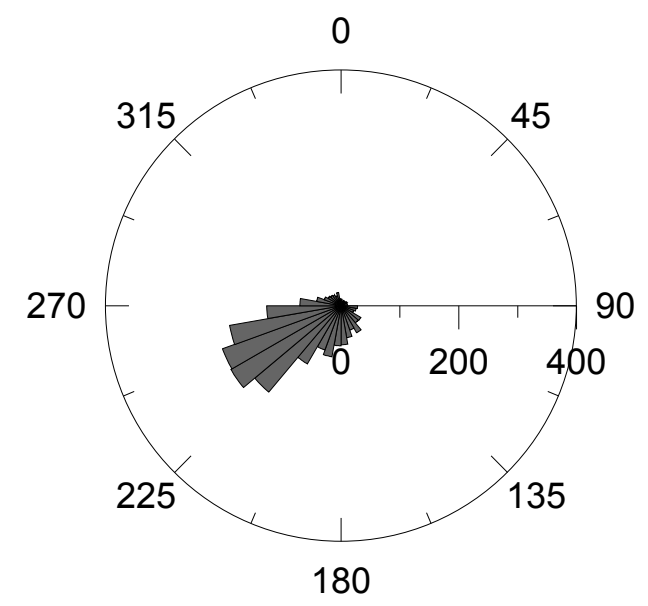

Fig. 5. Azimuth diagrams of total displacement vectors of the analyzed stations. Angle axis in degrees and radius axis represents the number of observed cases. 
The Pardubice

0

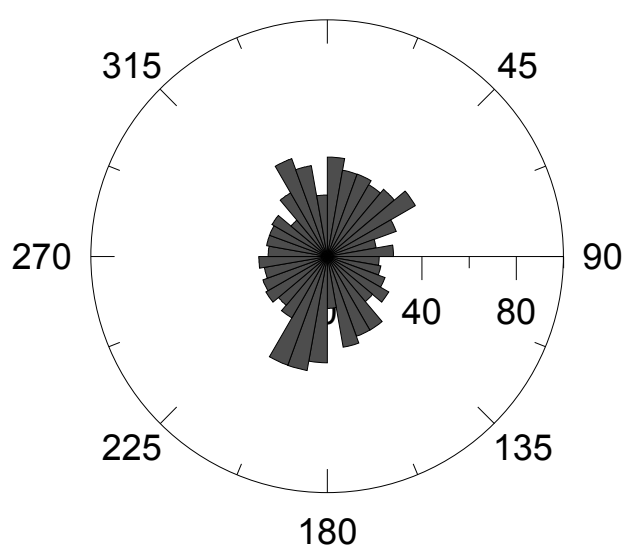

The Wałbrzych

0

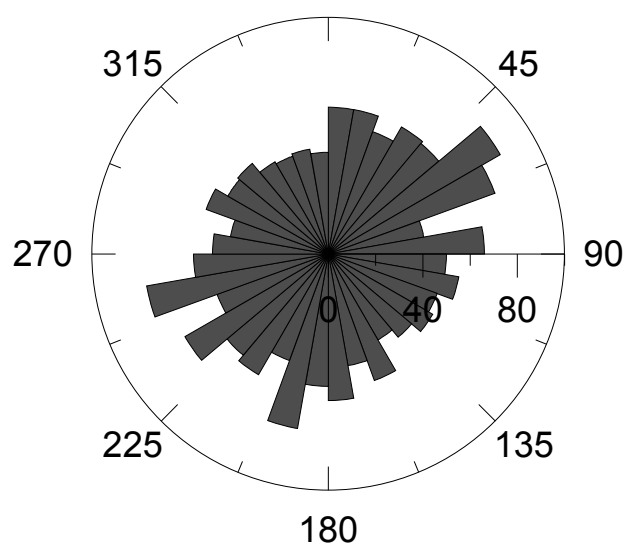

The Głogów

0

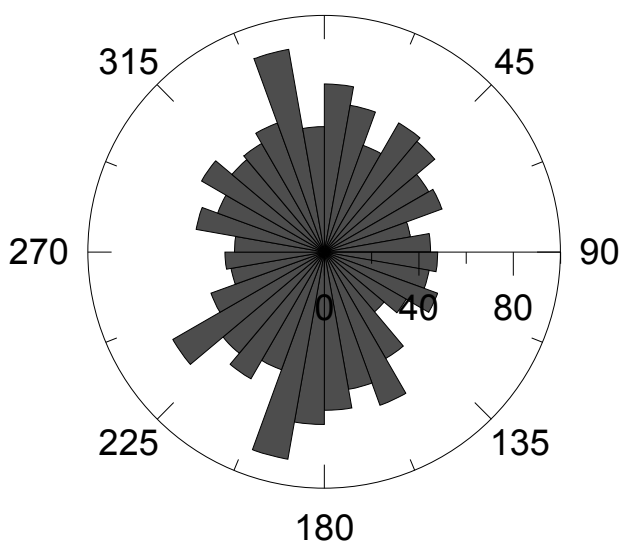

The Trutnov

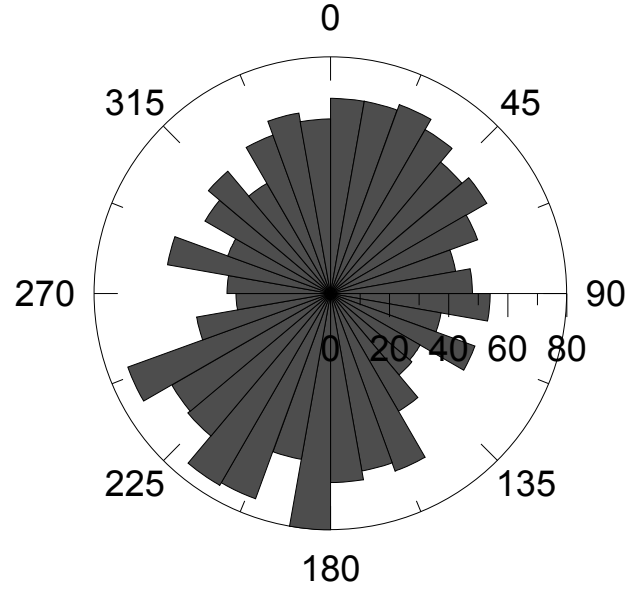

The Legnica

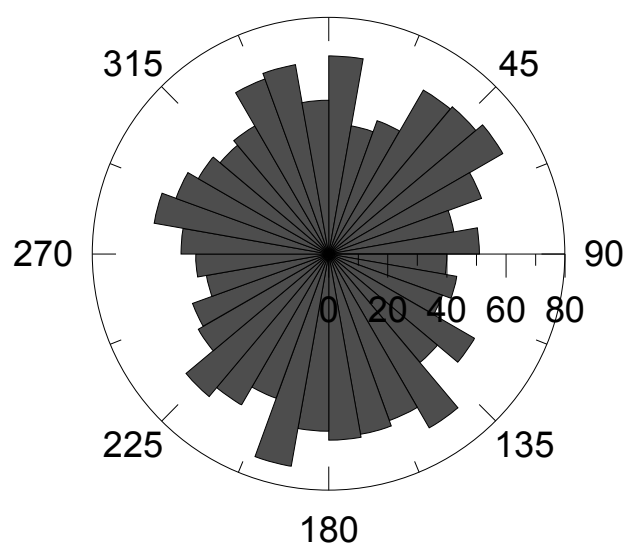

The Leszno

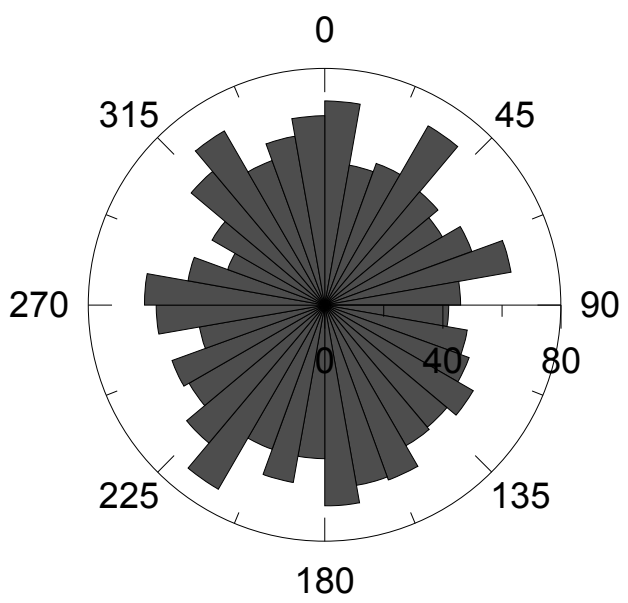

Fig. 6. Azimuth diagrams of daily displacement vectors of the analyzed stations. Angle axis in degrees and radius axis represents the number of observed cases. 
The Pardubice

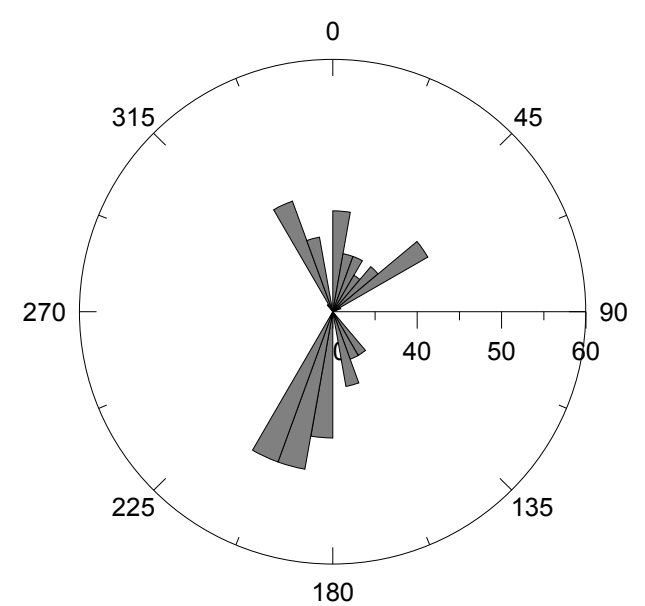

The Wałbrzych

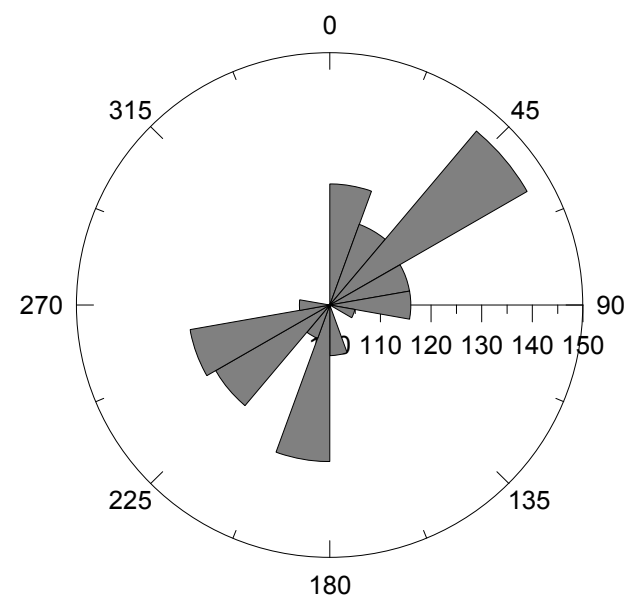

The Głogów

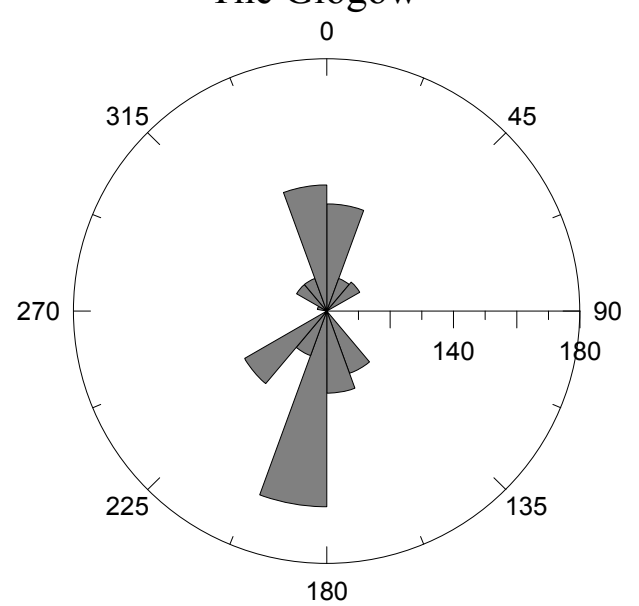

The Trutnov

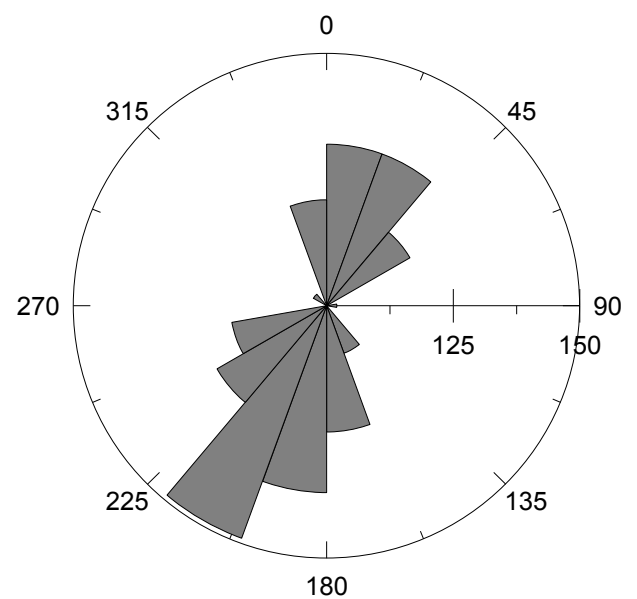

The Legnica

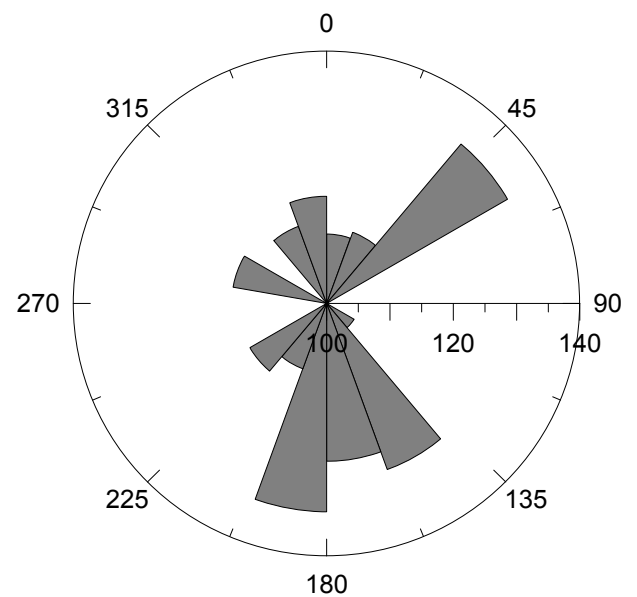

The Leszno

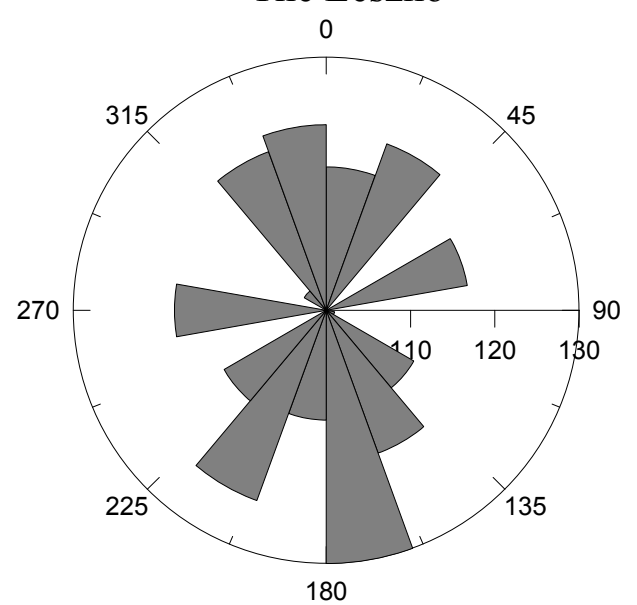

Fig. 7. Azimuth diagrams of daily over-represented displacement vectors of the analyzed stations. Angle axis in degrees and radius axis represents the number of observed cases. 


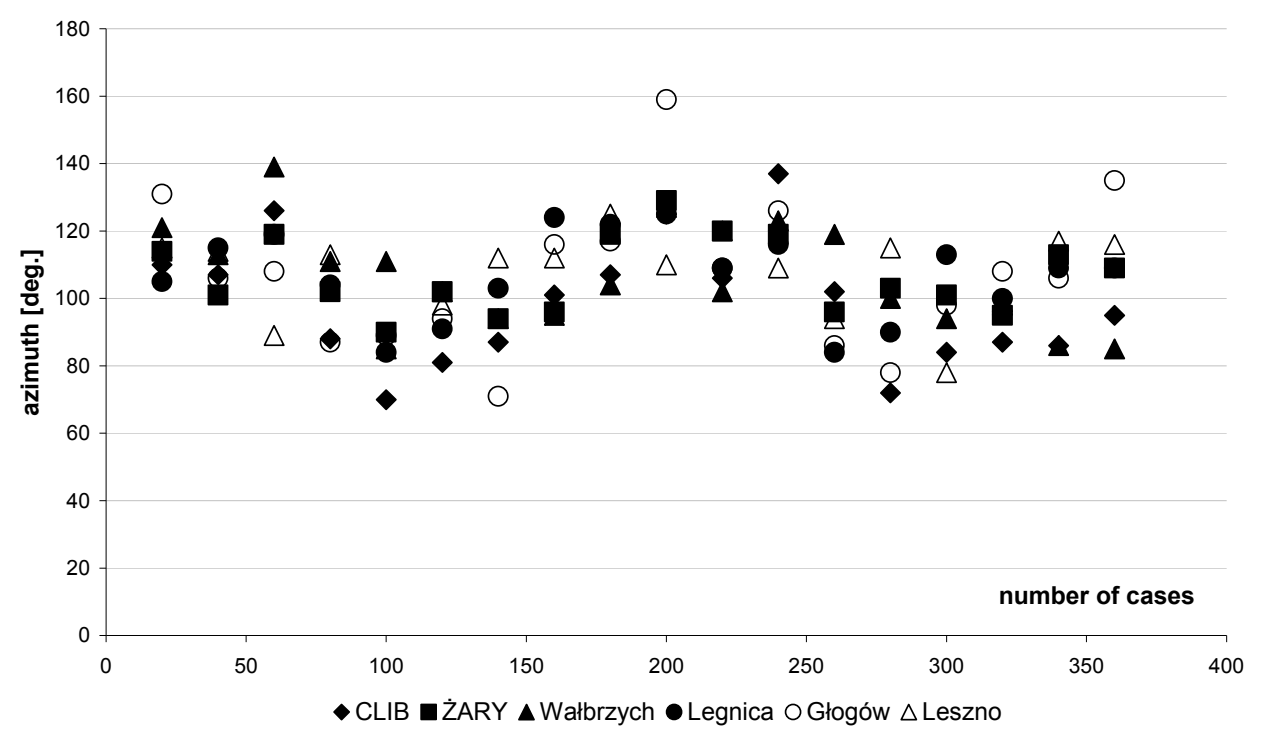

Fig. 8. Frequencies of azimuths of the stations. Distributions of 20 degree class intervals.

\subsection{Time dependency}

The mentioned events in a scope of time moments were analyzed for each station. No sequences in time were found. The events occurred in various moments in time: no week, month or year was a specific here. No clear pattern in co-occurrence of the events for the stations was found. Visual presentation of this problem and mentioned conclusion is a diagram in a form of calendar shown in Fig. 9. Black fields representing days when the over-represented azimuths of daily displacements occurred don't demonstrate a clear pattern.
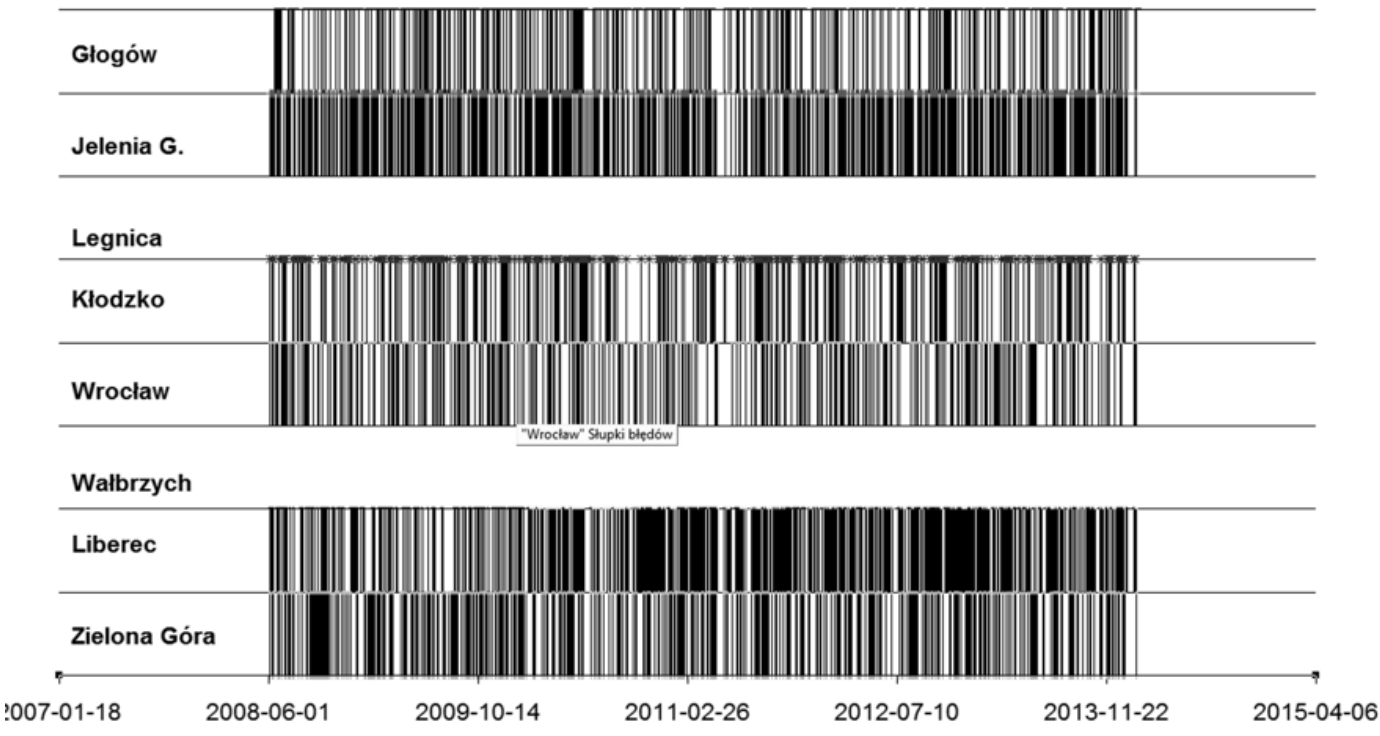

Fig. 9. Occurance (black fields) of azimuths of over-represented displacements of the stations. 


\subsection{Spatial relationships}

The spatio-temporal performance of horizontal displacements demonstrate some regularities. Although the displacement values are small and they oscillate around error of the determined components, there are some unexpected agreements in examined directions. So, orientations of geological structures were examined: faults and lineaments. The agreements of daily vector azimuths observed in most of the stations is a feature indicating a tendency of short-term variation of displacements: most of them are in S-N or SW-NE directions (Fig. 7). As the distance between station and the Sudetes decreases this tendency is more clear. So, it is less clear in the case of LESZ and LEGN - stations located more distant from the Sudetes. The directions of the over-represented daily vectors don't translate into orientations of total vectors - all of them are oriented toward to the Sudetes, only LEGN show a certain diversity, what can be related with effects of complicated pattern of faults. So, the Czech stations demonstrated total displacements with northern direction and the Polish stations - southern directions. They are similar directions to orientations of tectonic lines. As shown in Fig. 10 shows faults and lineaments of the area are in general perpendicular or parallel to orientations of the main tectonic zone in the area. Comparing orientations of geological line with azimuths of the daily and total displacement vectors of all the station relations look more evident (Fig. 11). Especially orientations of the daily vectors correspond to orientations of the lines. Although the relation with lineaments is not clear, they are often perpendicular to orientations of regional faults (WLBR, CTRU, NYSA etc.). Considering total displacements of all the stations the relationships with geological lines is not so clear but orientation toward the Sudetes with some exception (CLIB, JLGR) is confirmed. The most differencing is symmetric distribution of directions of daily vectors remaining wobbling movements. Total displacements are quite unambiguous. Daily displacements of stations located nearby the Sudetes show very good relation with stretch of the mountains: their orientations is perpendicular to the stretch (Fig. 12).

\section{Summary}

GNSS surveys carried out by reference stations of ASG-EUPOS provide data important for study of kinematics of tectonically active areas (as horizontal displacements). This paper presents the initial study on direction of displacement vectors of ASG- EUPOS stations in area of the Sudetes and their forefield. The area is assumed as a tectonically active but the author suggests that this activity is not a process which manifestation reveals in continuous displacements in short time by satellite-based methods. So, varying in time values of the displacement vector orientations (azimuths) are examined in the paper in the scope of their repeatability. There are conclusions drawn from the study as follows:

1. coordinate changes of the analyzed stations demonstrate infrequent tendencies in certain directions,

2. tendencies have a spatial sense but there is no regularity in time,

3. the spatial orientations (azimuths) of the tendencies reveal in total amount of changes in positions and in reference to a start moment or to previous day position. Compilation of the azimuths of all analyzed stations shows that they are not spatially accidental, 

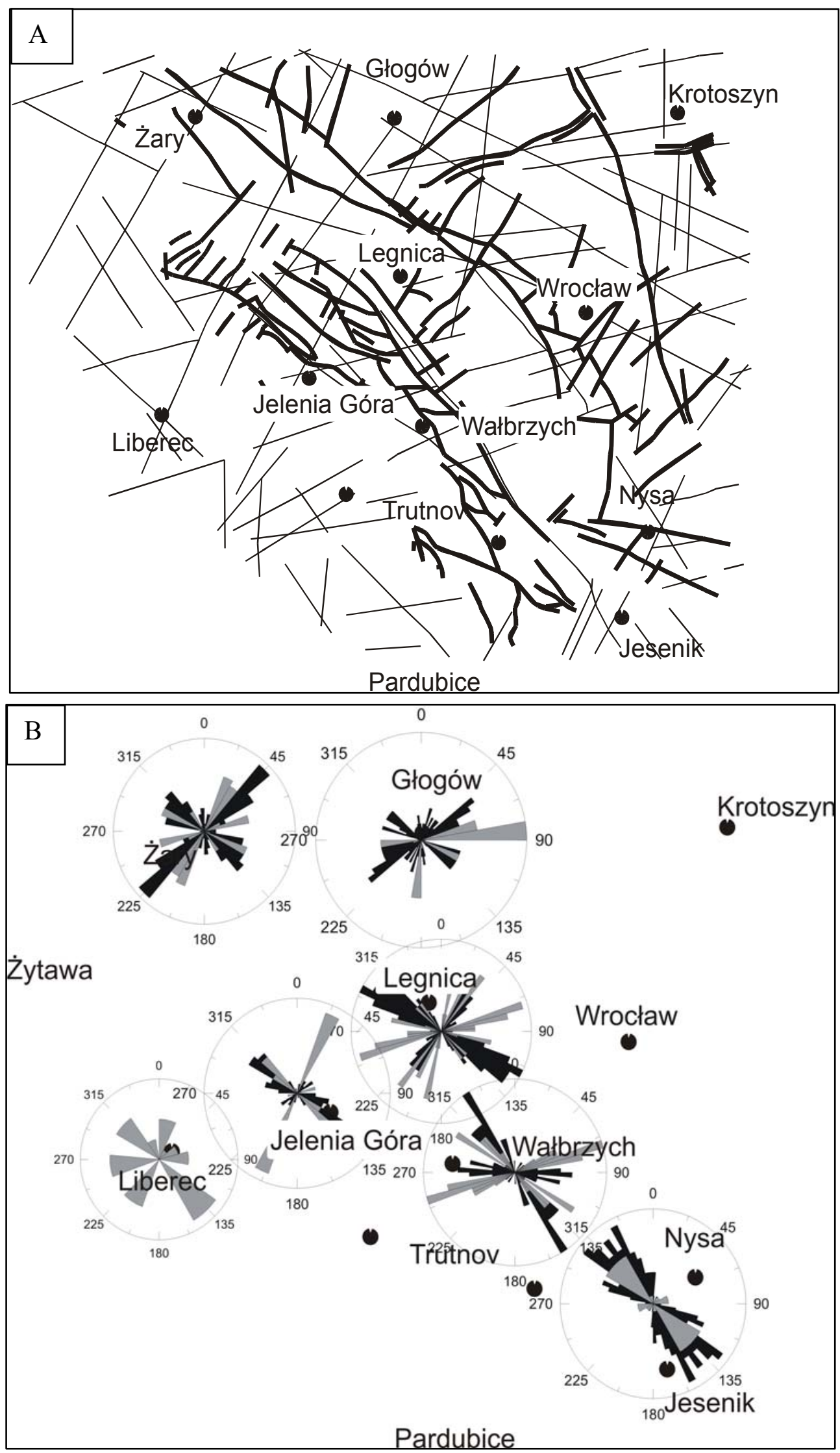

Fig. 10. Localization of lineaments (thin line) and faults (thick lines) in the studied area - A. Azimuth diagrams of faults (grey bins) and lineaments (black bins) - B. 

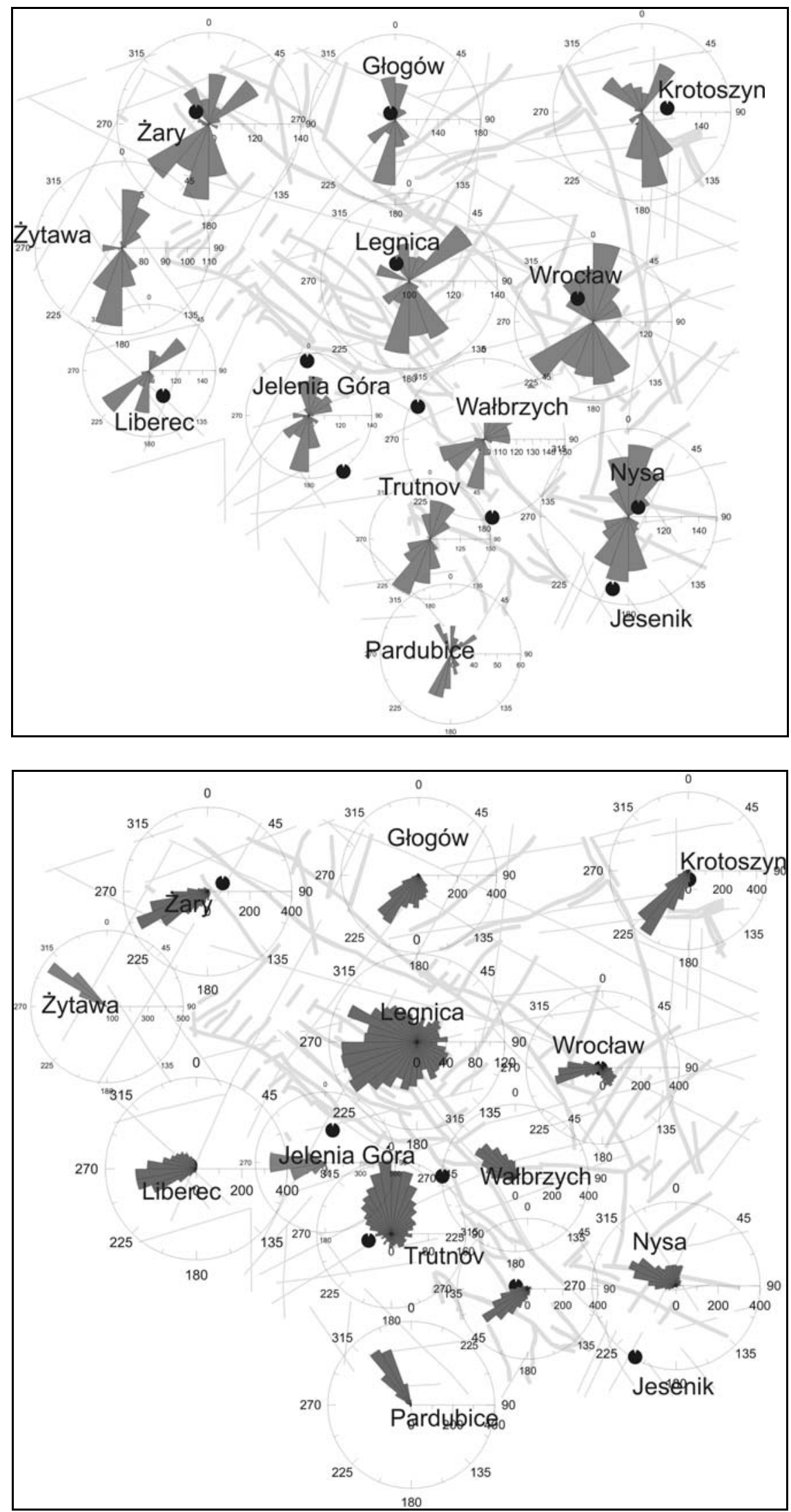

Fig. 11. Compilation of azimuth diagrams of over-represented daily displacements (upper map) and total displacement vectors (lower map) for all the stations with background of faults and lineament lines. 


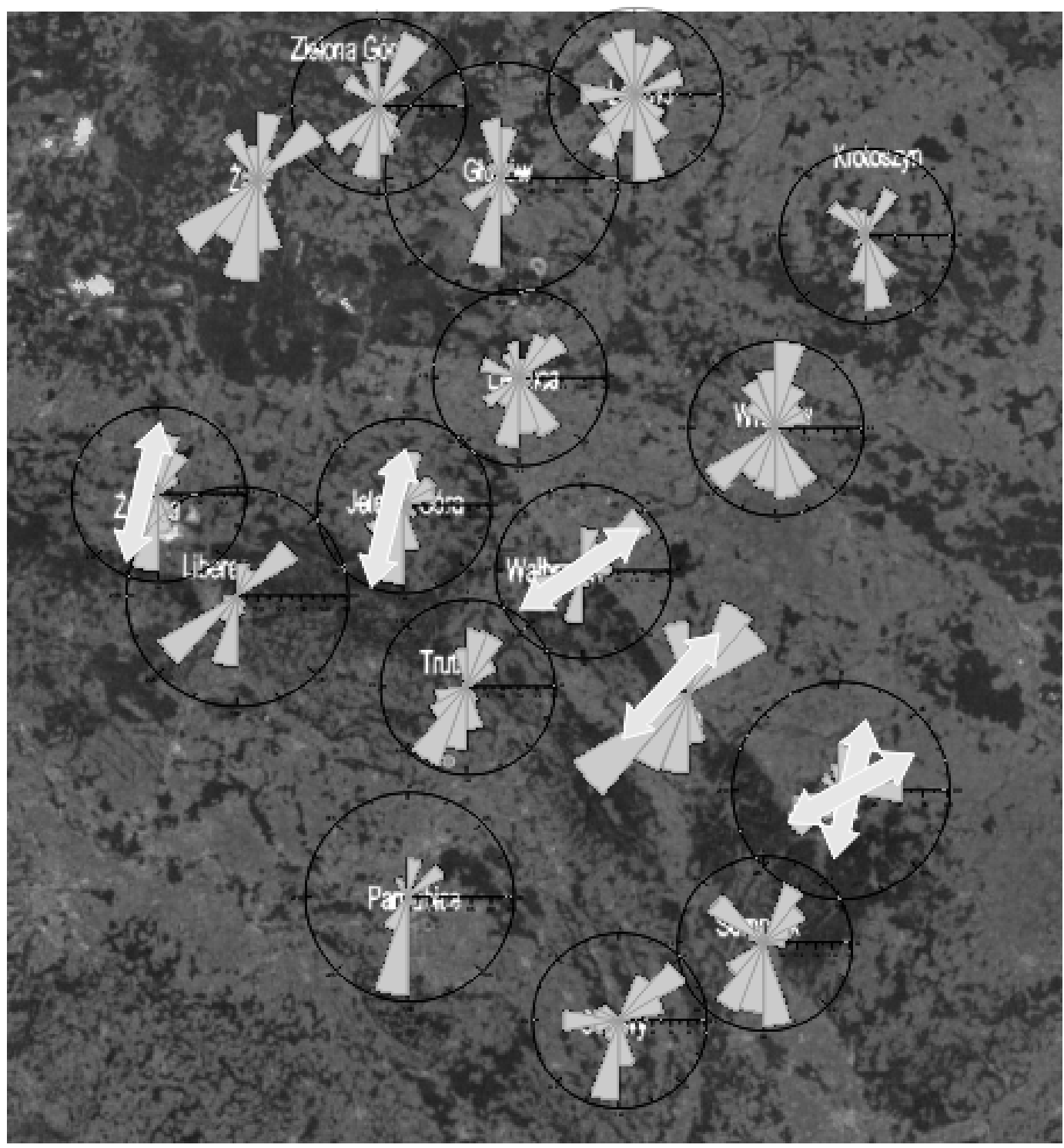

Fig. 12. Compilation of azimuth diagrams of over-represented daily displacements of all the stations. White arrows mark the azimuths of the stations situated nearby the Sudetes demonstrating their annular pattern.

4. comparing the azimuths and orientations of lineaments and faults some relations seems to be evident:

- in general azimuths of total displacements observed in the most stations are oriented accordingly toward to the Sudetes, this is more evident for the selected station located along longitudinal profile,

- variation of daily changes of N,E values look as spatially determined and they follow directions of geological lines, mainly faults; the directions are usually symmetrically distributed $\left( \pm 180^{\circ}\right)$ what remains wobble movements. The stations located nearby the Sudetes show usually daily changes toward to orientation of stretch of the mountains.

Relations between orientation of total displacement vectors with the Sudetes correspond to the result of height measurements discussed by Kaczmarek et al. 
(2016). The authors depicting areas of uplifts and subsidence. Discussed here horizontal displacements are oriented toward to centers of that subsidence.

Concerning two points highlighted at the end of chapter two, it can be stated that directions of temporal stations' position changes can be indication of impulse tectonic movements and their repeatability can be assumed as attribute depicting a response of tectonic stress release in a form of displacements.

For final ascertainments longer periods of time are necessary for analysis and statistical tests are to be made as the next stage of investigations.

\section{Acknowledgements}

The study presented here was carried out within statutory research project No. 11.11.150.195 at AGH University of Science and Technology, Faculty of Mining Surveying and Environmental Engineering, Department of Mining Areas Protection, Geoinformatics and Mining Surveying in Krakow. The work was supported by the Polish Ministry of Science and Higher Education and its grants for Scientific Research. Special thanks to Head Office of Geodesy and Cartography for making available the postprocessed data i.e. ETRF coordinates of the analyzed stations.

\section{References}

Araszkiewicz A., Bogusz J., Figurski M., Kroszczyński K., Szafranek K. (2009). Report from 30.06.2009 dealing with precise elaboration of observational data from permanent stations of ASG-EUPOS system. The Military Technical Academy. In Polish (Raport z dn. 30.06.2009 r. dotyczący precyzyjnego opracowania danych obserwacyjnych ze stacji permanentnych systemu ASG-EUPOS. Wojskowa Akademia Techniczna). Retrieved from:

http://www.asgeupos.pl/webpg/graph/img/ syst tests/20090630 WATCGS RaportASG-EUPOS.pdf

Bogusz J. (2015). Geodetic aspects of GPS permanent station non-linearity studies. Acta Geodyn. Geomater., vol. 12, No. 4 (180), 2015, pp. 323- 333, DOI: 10.13168/AGG.2015.0033.

Bogusz J., Figurski M., Kontny B., Grzempowski P.(2012). Horizontal velocity field derived from EPN and ASG-EUPOS satellite data on the example of southwestern part of Poland. Acta Geodynamica et Geomaterialia, vol. 9, No. 3(167), 2012, pp. 349-357.

Bosy J., Graszka W., Leończyk M.(2007).,ASG-EUPOS - a multifunctional precise satellite positioning system in Poland, European Journal of Navigation, Vol. 5 No. 4, Meckenheim, Germany 2007, pp. 30-34.

Brandt S. (1999). Analiza danych. Metody statystyczne i obliczeniowe. Wydawnictwo Naukowe PWN. Warszawa.

Butra J. and Kudełko, J. (2011). Rockburst hazard evaluation and prevention methods in Polish copper mines. Cuprum, 61(4), 2011, pp. 5-20.

Cacoń S., Bosy J., Kontny B. (2004). Recent Tectonic Activity in the Eastern Sudetes and on the Fore-Sudetic Block on the basis of 1993-2003 investigations. Reports on Geodety, Vol. 2 No. 69, Warszawa 2004, pp. 197-211.

Dyjor S. (1993). Etapy blokowego rozwoju Sudetów i ich przedpola w neogenie i starszym czwartorzędzie. Fol. Quatern., 64, Kraków, pp. 25-41. [In Polish].

Figurski M., Szafranek K., Bogusz J., Kamiński P.(2010). Investigation on stability of mountainous EUPOS sites' coordinates. Acta Geodyn. Geomater., Vol. 7, No. 3 (159), pp. 263-274. 
Graniczny M. and Mizerski W. (2003). Lineamenty na zdjęciach satelitarnych Polski próba podsumowania. Przegląd Geologiczny, Vol. 51, No. 6, pp. 474-482. [In Polish].

Grygar R. and Jellnek J. (2003). The Upper Morava and Nysa pull-apart grabens the evidence af neotectonic dextral transtension on the Sudetic fault system. Acta Montana. Ser. A. No. 24. Vol. 131, pp. 1-59.

Hefty L. and Gerhátová L. (2012): Potential of precise point positioning using $1 \mathrm{~Hz}$ GPS data for detection of seismic-related displacements. Acta Geodynamica et Geomaterialia, Vol. 9, No. 3 (167), pp. 303-313.

Kaczmarek A., Cacoń S and Weigel J.(2016). Recent relative vertical movements in the tectonic zone of the Sudety Mts. Acta Geodyn. Geomater., vol. 13, No. 2 (182), pp. 177-184. DOI: 10.13168/AGG.2015.0055.

Kaczorowski M. and Wojewoda J. (2011). Neotectonic activity interpreted from a long water-tube tiltmeter record at the SRC Geodynamic Laboratory in Ksiaz, Central Sudetes, SW Poland. Acta Geodyn. Geomater., Vol. 8, No. 3 (163), pp. 249-261.

Klos A., Bogusz J., Figurski M., Kosek W. (2015). Irregular variations in the GPS time series by the probability and noise analysis. Survey Review, Vol. 47, Issue 342, pp. 163-173. DOI: 10.1179/1752270614Y.0000000133.

Kontny B. and Bogusz J. (2012). Models of vertical movements of the earth crust surface in the area of Poland derived from leveling and GNSS data. Acta Geodynamica et Geomaterialia, Vol. 9, No. 3 (167), 2012. pp. 331-337.

Kontny B. (2003). Geodezyjne badania współczesnej kinematyki głównych struktur tektonicznych polskich Sudetów i bloku przedsudeckiego na podstawie pomiarów GPS. Zesz. Nauk. AR Wroc. No. 468. Rozprawy, pp. 1- 146. [In Polish].

Liszkowski, J.: 1982, The origin of recent vertical crustal movements in Poland. Rozprawy Uniwersytetu Warszawskiego, No. 174, Warszawa, pp. 1-179. [In Polish].

Orlecka-Sikora, B., Papadimitriou, E. E., Kwiatek, G. (2009). A study of the interaction among mining-induced seismic events in the Legnica-Głogów Copper District, Poland. Acta Geophysica, Vol. 57, No. 2, pp. 413-434. https://www.irsm.cas.cz/materialy/acta content/2007 04/2 Wojewoda.pdf DOI: 10.2478/s11600-008-0085-z.

Pilecka E.(2007). Statistical analysis of the relation between locations of high energy epicenter tremors and lineaments in areas of the Upper Silesian Basin. Gospodarka Surowcami Mineralnymi, Vol. 23, No. 4. PAN IGSMiE, Kraków, pp. 101-109. [In Polish].

Pilecka E. (2008). An analysis of lineament directions on satellite images in context of the occurrence of an induced seismicity in the Legnica-Głogów Copper District (LGCD). Gospodarka Surowcami Mineralnymi, Vol. 24, No. 2/3. PAN IGSMiE, Kraków, pp. 135-146. [In Polish].

Salski W. (1996). The tectonics of the deposit. In Polish: Tektonika złoża. In: Monografia KGHM Polska Miedź S.A. (editor: A. Piestrzyński). Pub.: Profil, Kraków. [In Polish].

Schenk V. and Schenková Z. (2008). Geodynamic Pattern of the West Bohemia Region based on permanent GPS measurements. Studia geophysica et geodetica, Vol. 53, Issue 3, pp. 329-341. DOI: 10.1007/s11200-009-0021-y.

Szczerbowski Z. and Jura J. (2016). Mining induced seismic events and surface deformations monitored by GPS permanent stations. Acta Geodynamica et Geomaterialia. Vol. 12 No. 3 (179), pp. 237-248. DOI: 10.13168/AGG.2015.0023. 
Wojewoda J. (2007). Neotectonic aspect of the intrasudetic shear zone. Acta Geodynamica et Geomaterialia, Vol. 4. No. 4 (148), pp. 31-41.

Znosko J. (1981). The problem of oceanic crust and of ophiolites in the Sudetes. Bull. Acad. Pol. Sc., Ser. Sc. de la Terre, 29, pp. 185-197.

\section{Authors:}

Zbigniew Szczerbowski ${ }^{11}$, szczerbo@agh.edu.pl;

1) AGH University of Science and Technology,

Faculty of Mining Surveying and Environmental Engineering,

Department of Mining Areas Protection, Geoinformatics and Mining Surveying,

al. A. Mickiewicza 30, 30-059 Kraków, Poland, 